www.nature.com/ejhg

\title{
A candidate region for Asperger syndrome defined by two 17p breakpoints
}

\author{
Dmitry Tentler ${ }^{1}$, Tonnie Johannesson ${ }^{2}$, Maria Johansson ${ }^{3}$, Maria Råstam³ \\ Christopher Gillberg $^{3}$, Christina Orsmark ${ }^{1}$, Birgit Carlsson ${ }^{1}$, Jan Wahlström ${ }^{2}$ and \\ Niklas Dahl*,1
}

\begin{abstract}
${ }^{1}$ Department of Genetics and Pathology, Section of Clinical Genetics, The Rudbeck Laboratory, Uppsala University, Uppsala, Sweden; ${ }^{2}$ Department of Clinical Genetics, Gothenburg University, Gothenburg, Sweden; ${ }^{3}$ Department of Child and Adolescent Psychiatry, Gothenburg University, Gothenburg, Sweden, and St. George's Hospital Medical

School, London, UK
\end{abstract}

\begin{abstract}
Asperger syndrome (AS) is a mild form of autistic disorder characterised by impairment in social interaction as well as a restricted pattern of behaviour, interests, and activities. Two patients with AS and balanced translocations $t(13 ; 17)$ and $t(17 ; 19)$, respectively, were identified. Fluorescent in situ hybridisation (FISH) analysis with chromosome 17 specific clones to metaphase chromosomes from both patients showed that the chromosome 17 breakpoints are located within a $300 \mathrm{~kb}$ region at 17p13. The region spans 14 known genes. The expression of these genes was analysed in lymphoblastoid RNA derived from the patients and healthy control individuals. The CHRNE, DKFZP566H073, LOC90048, PFN1, SPAG7, KIAA0909, ZNF232 and KIF1C genes showed similar levels of expression in cell lines with the translocations when compared with cell lines with normal karyotype. No expression was detected for the MINK, GP1BA, SLC25A11, ENO3, FLJ10060 and USP6 genes in any of the cell lines. The close physical relation of the two 17p breakpoints suggest a common genetic aetiology for the phenotype in the patients. Structural and functional analysis of the genes located around the two 17p breakpoints in $t(13 ; 17)$ and $t(17 ; 19)$ patients may reveal candidate sequences for the AS phenotype. European Journal of Human Genetics (2002) 11, 189-195. doi:10.1038/sj.ejhg.5200939
\end{abstract}

Keywords: Asperger syndrome; autism; balanced translocation; candidate region

\section{Introduction}

Autistic disorder includes a broad spectrum of manifestations and symptoms. Childhood autism (Kanner syndrome) is characterised by abnormalities in development of social interaction, communication and imagination, which are apparent before the age of 3 years. Mental retardation, aggression and absence of speech are often present in severe cases. Other neurological disorders may overlap with childhood autism (autism spectrum disorders) with different degree of manifestations (see Gillberg and Billstedt ${ }^{1}$ for a

\footnotetext{
*Correspondence: Niklas Dahl; Department of Genetics and Pathology, Unit of Clinical Genetics, Rudbeck Laboratory, S-751 85 Uppsala, Sweden. Tel: +46 1861127 99; Fax: +46 185540 25;

E-mail: niklas.dahl@genpat.uu.se

Received 22 February 2002; revised 25 November 2002; accepted 27 November 2002
}

review). Asperger syndrome (AS) has been conceptualised as a mild form of autistic disorder (high-functioning autism). The essential features of Asperger syndrome are severe and sustained impairments in social interaction and the development of restricted repetitive patterns of behaviour, interests and activities. Asperger syndrome is diagnosed almost exclusively in individuals with normal or high level of intelligence. A genetic factor behind autism has been proposed, and search for autism candidate regions has been performed by different groups. ${ }^{2,3}$ Several genomic screen studies have revealed susceptibility loci for autism on chromosomes 1, 2, 5, 6, 7, 8, 13, 16, 18, 19 and $\mathrm{X}^{4-11}$ Cytogenetic abnormalities involving chromosomes 7 and 15 in patients with autism have been reported ${ }^{3}$ but molecular analyses of these chromosomal regions have failed to reveal alleles or genes associated with autism. ${ }^{12-15}$ 
In this report, we present the clinical, cytogenetic and molecular findings in two non-related patients with AS. The two patients carry apparently balanced reciprocal translocations involving 17p. We suggest that the phenotype in these patients results from a direct or a positional effect of the breakpoints on chromosome 17.

\section{Materials and methods \\ Case reports}

Case 1 The first patient was a 19 year old man, born after 42 gestational weeks by elective caesarean section. Birth weight, length, and head-circumference were $3560 \mathrm{~g}$, $51 \mathrm{~cm}$, and $36.5 \mathrm{~cm}$, respectively. He was the first child to a 23-year-old mother. He had two younger half-sisters, one of whom has autism. The other half-sister has ADHD (Attention Deficit-Hyperactivity Disorder) and DCD (Developmental Coordination Disorder). The mother has a history of anorexia nervosa and obsessive personality traits but autism was excluded. At the age of 11 years, the patient met Gillberg criteria for $\mathrm{AS}^{16}$ according to ASDI-interview ${ }^{17}$ : (i) social impairment; (ii) narrow interests; (iii) repetitive routines; (iv) speech and language peculiarities; (v) nonverbal communication problems; and (vi) motor clumsiness (scores 3,3,2,3,2,1; cut-off scores 2,1,1,3,1,1). At the age of 13 years, a new evaluation showed that he met 11 of 16 criteria for autistic disorder according to DSM-III-R (cut-off score 8 ) and, at age 19 years, he also met the ADI-R algorithm criteria for childhood autism (scores of 12, 11 and 7 for social, communication and behaviour problems, respectively). ${ }^{18}$ Cytogenetic analysis revealed that he has an apparently balanced translocation $\mathrm{t}(13 ; 17)(\mathrm{q} 14 ; \mathrm{p} 13)$. Both parents and the half-sisters have normal karyotypes.

Case 2 The cytogenetic findings of the second patient was described previously ${ }^{19}$ and we performed re-evaluation of the patient's clinical conditions. The patient is a 20 -yearold man. He was the third-born child to a 34-year-old mother and had three healthy brothers. The parents are healthy and without a family history of mental or behavioural disorders. The pregnancy and delivery were uneventful. Birth weight, length, and head-circumference were $3280 \mathrm{~g}, 50 \mathrm{~cm}$, and $34 \mathrm{~cm}$ respectively. During the first year, the patient had fever-related seizures. Speechand motor development during infancy was normal. At the age of 20 years, he met criteria for $\mathrm{AS}^{16}$ in all subdomains according to ASDI-interview: Social impairment, narrow interests, repetitive routines, speech and language peculiarities, non-verbal communication problems and motor clumsiness (scores 3,1,1,3,3,1; cut-off scores $3,1,1,3,1,1)$. He met five DSM-III-R criteria for autistic disorder (cut-off score 8). He did not fulfil the ADI-R algorithm criteria for childhood autism (scores of 7, 4 and 3 for social, communication and behaviour problems, respectively). Cytogenetic analysis revealed an apparently balanced translocation $\mathrm{t}(17 ; 19)(\mathrm{p} 13.3$; cen). Both parents have normal karyotypes.

\section{Genomic probes}

The chromosome 17 specific YAC clones were obtained from the Fondation Jean Dausset-C.E.P.H. YAC/BAC services. The PAC and BAC clones were obtained from Resource Centre/Primary Database (RZPD) of the German Human Genome Project. Single-copy genomic probes for Southern hybridisation were obtained by PCR amplification using BAC DNA. The list of primers used for the amplification of probes is presented in Table 1. The PCR fragments were separated in a $1 \%$ agarose gel and purified by QIAquick gel extraction kit (Qiagen).

\section{Cytogenetic and FISH studies}

Standard chromosome preparations were made either from PHA-stimulated peripheral blood lymphocytes or from EBVtransformed B-lymphocytes.

Fluorescent in situ hybridisation was performed essentially as previously described. ${ }^{20,21}$ Purified PAC and BAC DNA were labelled with digoxigenin-16-dUTP (Boehringer Mannheim) by nick-translation. Total yeast DNA containing a specific YAC was purified by the spheroplast method $^{22}$ followed by digestion with EcoRI and labelling with digoxigenin-16-dUTP by nick-translation. The probes were detected by the application of a single layer of rhodamine labelled anti-digoxigenin (Boehringer Mannheim).

Table 1 Primers used for amplification of PCR-derived probes applied for mapping of the 17p translocation breakpoint in $\mathrm{t}(17 ; 19)$ patient

\begin{tabular}{llll}
\hline Probe name & Forward primer $\left(5^{\prime}-3^{\prime}\right)$ & Reverse primer $\left(5^{\prime}-3^{\prime}\right)$ & Fragment size $(b p)$ \\
\hline ENO1 & TCAAGTCATCCCCCACAATC & CTTCGAACCCAACATCCT & 771 \\
PFN1 & TTGAGGTGCTTTTTGTGTG & GGTTTTGGCAGCAATAAGGG & 783 \\
SLC25A11 & TTCCTCCCCTCCCTGTGTC & AGTACCATCAGCCCCAGTCA & 617 \\
GP1BA & GGCTTTGGGGGGACTTG & CAGACCTGCCAAAGAACA & 826 \\
GOOD & CATGCCCTTCCCAGATT & GCCAGAGATGAGAGGAAC & 713 \\
CYBER1 & ACGAGGATGAACATGGCAG & AGTCACGGGTGCTTTATCTT & 265 \\
CYBER2 & GGCTGGGTTGCTAGAGGG & TCCGCTCTCTGCTCCTCTC & 322 \\
CHRNE & AGGCAGAGGGGAGAGAGGT & ATCGAAGGGGAAGTAGGTG & 874 \\
MINK1 & CTGGGGGATCGGGCTG & CAAGAATAACAAGCAGCAGA & 717 \\
\hline
\end{tabular}


Chromosomes were counterstained using DAPI (Serva), and mounted in Vectashield anti-fading solution (Vector Labs). The slides were analysed with a Zeiss Axioscope microscope. Images were merged using a cooled CCD camera (Photometrics) and the IPlab software (Vysis).

\section{Southern blot hybridisation}

Genomic DNAs were isolated from peripheral blood obtained from patients and normal control individuals using standard procedures. Southern blot and hybridisation were carried out essentially as described. ${ }^{23}$ Ten $\mu \mathrm{g}$ of DNA was digested with the appropriate restriction enzyme; fragments were separated on $0.8 \%$ agarose gel, transferred to Hybond-N+ membrane (Amersham), and hybridised with probes labelled with ${ }^{32} \mathrm{P}$-dCTP by random priming.

\section{Northern slot hybridisation}

Total RNA was purified from EBV-transformed B-lymphocytes by TRIzol Reagent (Life Technologies) according to the manufacturer's instructions. The patients and normal control RNAs were transferred to Hybond $\mathrm{N}+$ membrane (Amersham) using Bio-Dot SF microfiltration unit (Bio-Rad Laboratories) by the method described in Sambrook et $a^{23}$ The RNAs were applied to the membrane in separate slots $(20,10,5,2.5,1.25 \mu \mathrm{g}, 625,312$ and $156 \mathrm{ng}$, respectively). The membranes were hybridised to oligonucleotide probes derived from the mRNA sequences (Table 2).

The oligonucleotides were labelled with ${ }^{32} \mathrm{P}-\mathrm{ATP}$ by the following procedure: The reaction mixture containing $5 \mu \mathrm{l}$ of an oligonucleotide $(10 \mathrm{ng} / \mu \mathrm{l}), 5 \mu \mathrm{l} 10 \times \mathrm{T} 4$ polynucleotide kinase buffer (New England BioLabs), $2 \mu \mathrm{l}$ T4 polynucleotide kinase $(10 \mathrm{U} / \mu \mathrm{l}), 5 \mu \mathrm{l} \gamma^{32} \mathrm{P}$-ATP $(10 \mathrm{mCi} / \mathrm{ml})$ and $33 \mu \mathrm{l} \mathrm{H}_{2} \mathrm{O}$ was incubated at $37^{\circ} \mathrm{C}$ for $75 \mathrm{~min}$ followed

Table 2 Oligonucleotide probes used for Northern slot hybridisation

\begin{tabular}{ll}
\hline Gene name & Oligonucleotide sequence $\left(5^{\prime}-3^{\prime}\right)$ \\
\hline MINK1 & TCTTTCAGCAACACAAAGTCTGCGGGC \\
MINK2 & TCCTCACCAATGCTCGCTTATAGCTT \\
CHRNE & CAGAAGCAGATGTTGTAAGGCATTC \\
GP1BA & CTGAAATTGTGTGCCTGTGTTGTGAAG \\
SLC25A11 & TGAGTCCAGTAAGAACTGCTTGGATTG \\
DKFZP56H073 & TTCCTCACTATTCCACACCATGTTCA \\
LOC90048 & AGAGAGGAACAAGGTGAAGCACCT \\
PFN1 & TGCTCTTGGTACGAAGATTTATGCTAA \\
ENO3 & CTCTTAGTTCCAGAGCCTCATAGATAC \\
SPAG7 & TGTAGTATGCTCCTCTCGATTTGTC \\
KIAA0909 & TTCGATGATCTGCTTGGCTAGTGAGA \\
KIF1C & TCTTCATTCTCATCCTCATGATCCTGG \\
FLJ10060 & TCTTCTGGAAATGAAGACCTTCTAGT \\
ZNF232 & TCAGTAATGGTGGTTGTGGCATGAT \\
USP6 & GCTTGTGAATACCACTGCGTGTGTGTA \\
28S & AACGATCAGAGTAGTGGTATTTCACC \\
ACTB & ACAACAATGTGCAATCAAATCCTCG \\
\hline
\end{tabular}

by a purification from unincorporated nucleotides with QIAquick nucleotide removal kit (Qiagen). Oligonucleotides with a specific activity of $7-15 \times 10^{8} \mathrm{cpm} / \mu \mathrm{g}$ were used for hybridisation.

Pre-hybridisation was carried out in a solution containing $20 \%$ formamide, $5 \times$ Denhardt's reagent, $10 \mathrm{~mm}$ phosphate buffer $\mathrm{pH} 7.0,0.1 \%$ SDS and $100 \mathrm{ng} / \mu \mathrm{l}$ sonicated salmon sperm DNA at $37^{\circ} \mathrm{C}$ for $30 \mathrm{~min}$. The labelled oligoprobe $(50 \mathrm{ng}$ ) was then added to the hybridisation solution and incubated at $37^{\circ} \mathrm{C}$ overnight. In case of $28 \mathrm{~S}$ oligo (Table 2), $500 \mathrm{ng}$ of the cold oligonucleotide was also added. ${ }^{24}$ The post-hybridisation washing of the membranes was performed twice in $2 \times \mathrm{SSC} / 0.1 \%$ SDS at $42^{\circ} \mathrm{C}$ for $15 \mathrm{~min}$ and once in $0.1 \times \mathrm{SSC} / 0.1 \% \mathrm{SDS}$ at $42^{\circ} \mathrm{C}$ for $5 \mathrm{~min}$. The signals were analysed with a PhosphoImager.

The amount of RNA was quantified by hybridisation with oligonucleotide probes to $28 \mathrm{~S}$ RNA and $\beta$-actin (ACTB) RNA. In order to identify possible DNA contamination in the RNA sample, membranes were hybridised to oligonucleotides complementary to the oligo-probes.

\section{Results}

Mapping the chromosome 17 translocation breakpoints The cytogenetic analysis of the two Asperger syndrome patients revealed apparently balanced translocations $\mathrm{t}(13 ; 17)(\mathrm{q} 14 ; \mathrm{p} 13)$ and $\mathrm{t}(17 ; 19)(\mathrm{p} 13 ;$ cen $)$, respectively. Both translocations were found to be de novo, since the parents had normal karyotypes. Further mapping of the chromosome 17 breakpoints was performed by FISH analysis. Five YAC clones on $17 \mathrm{p} 13$ were initially chosen as probes (Whitehead Institute/MIT Center for Genome Research; http://carbon.wi.mit.edu:8000/cgi-bin/contig/phys_map).

Fluorescent in situ hybridisation of the YAC clones to metaphase chromosomes from the patients showed that both $17 \mathrm{p}$ breakpoints were located in the region between clones 898_a_10 and 961_c_4.

Further FISH analysis with PAC and BAC clones located in the region restricted both breakpoints to a region flanked by the clones RP11-177H5 and RPCIP-1193O3. The region is covered by the chromosome 17 working draft sequence segment NT_010823. Using the GenBank (http:// www.ncbi.nlm.nih.gov) information, we constructed a physical map (Figure 1) spanning the 17p breakpoints. The analysis revealed that the $17 \mathrm{p}$ breakpoint derived from the $t(17 ; 19)$ was located in the overlapping region of the clones RP11-81A22, RP11-177H5 and RP11-305G1 (Figure 2), whereas the clones RP11-46I8, CTD-2013F15 and RP11$333 \mathrm{E} 1$ spanned the $17 \mathrm{p}$ breakpoint derived from the $t(13 ; 17)$ (Figure 1$)$. The FISH analyses gave no indications of other rearrangements or deletions.

Southern blot analysis was performed in order to map the $17 \mathrm{p}$ breakpoint position in the $t(17 ; 19)$ patient more precisely. Genomic probes derived from the NT_010823 sequence were hybridised to DNAs from the patient and normal controls digested by ApaLI, EcoRI or SphI restriction 


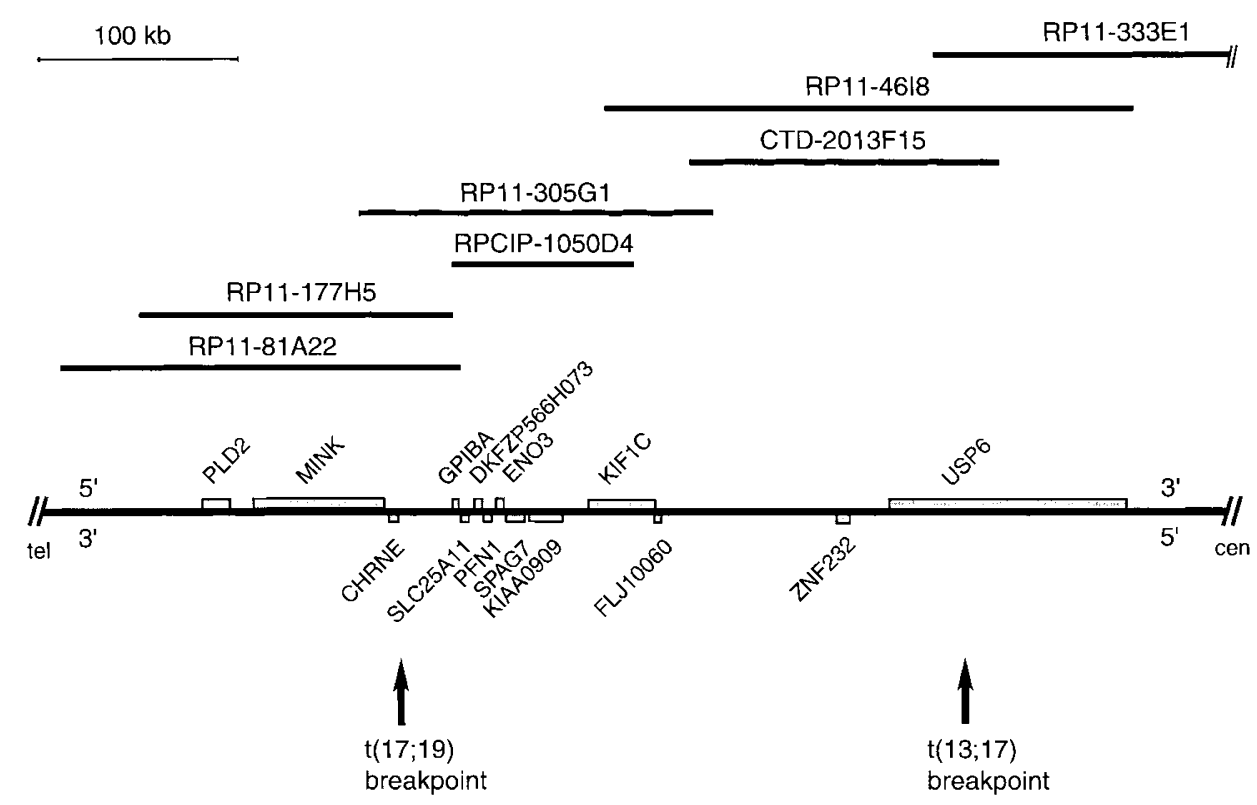

Figure 1 Physical map of the chromosome 17 region, which spans the breakpoints. The relative positions of PAC and BAC clones used for FISH mapping of the breakpoints are shown (top). The positions of the two breakpoints are indicated by arrows (bottom). The left breakpoint is mapped to a $0.7 \mathrm{bp}$ region and the right to a $25-30 \mathrm{~kb}$ region. Genes located in the region are indicated by grey boxes. Genes transcribed towards the centromere are indicated above the line whereas genes transcribed in the opposite direction are placed below the line.

Table 3 Genes selected for the investigation of their expression level in $t(17 ; 19)$ and $t(13 ; 17)$ patients

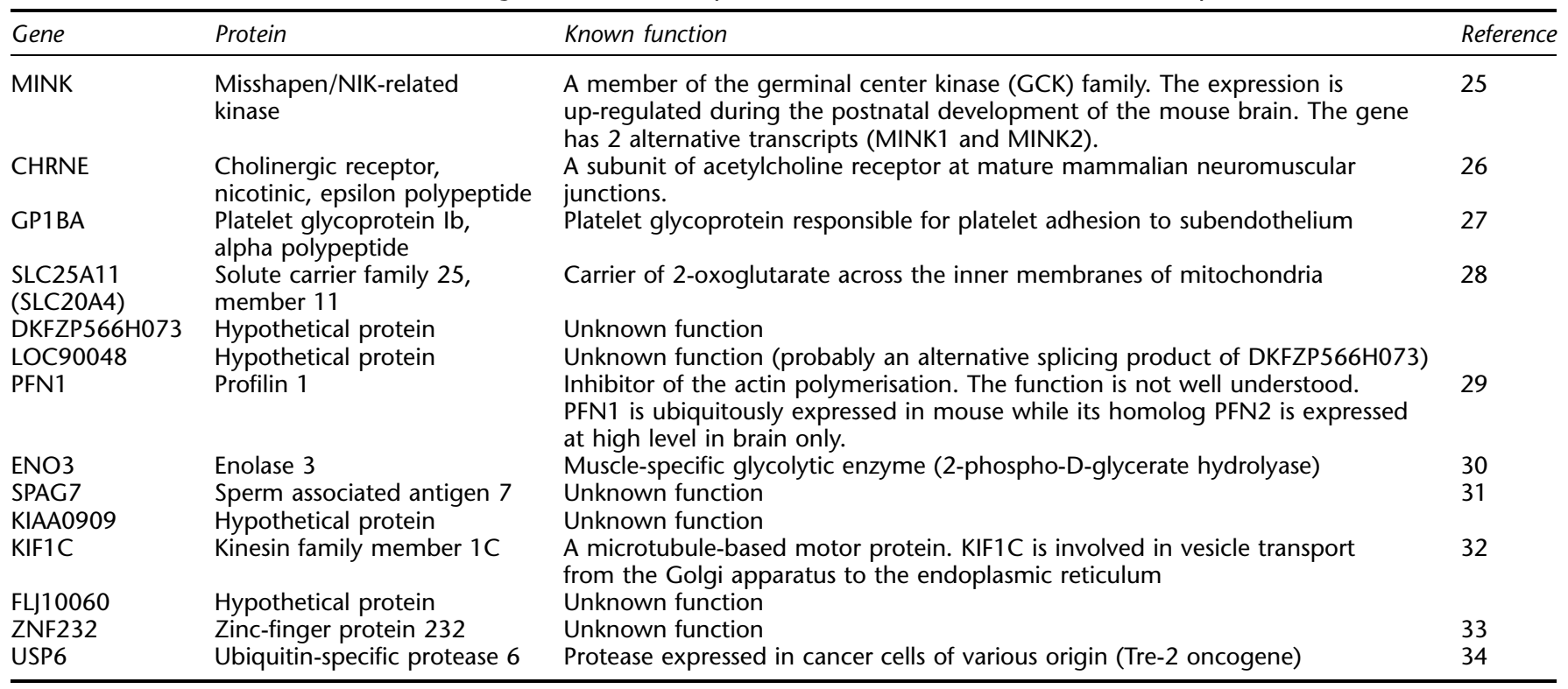

enzymes. Abberant bands were detected in the patient DNA digested with ApaLI and EcoRI enzymes when hybridised with the CHRNE probe (Table 1). The result indicates that the breakpoint is positioned within a $0.7 \mathrm{~kb}$ region located between the CHRNE and GP1BA genes and, $0.8 \mathrm{~kb}$ away from the $5^{\prime}$ end of the CHRNE gene. From the Southern analyses there were no indications of complex rearrangments or deletions.

In summary, the results indicate that the two $17 \mathrm{p}$ breakpoints in the patients are separated by 250- 
A

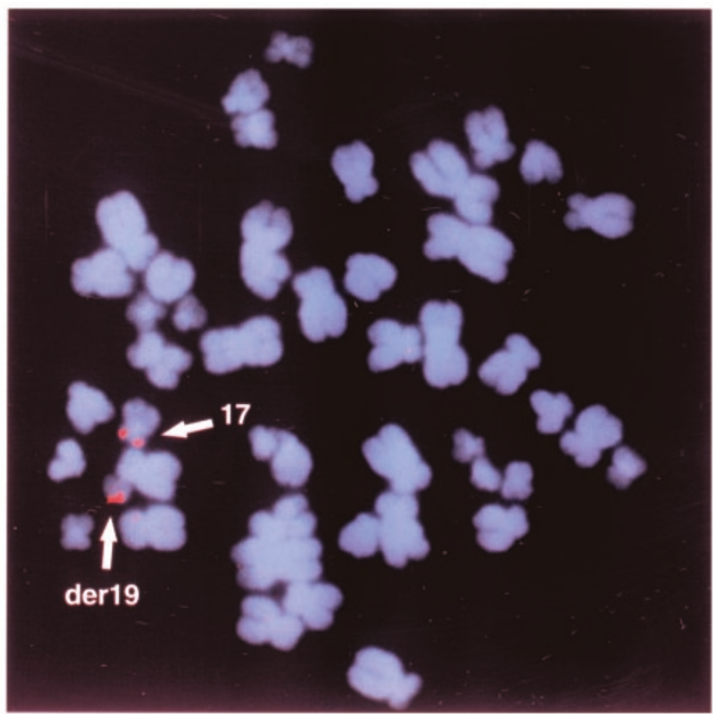

B

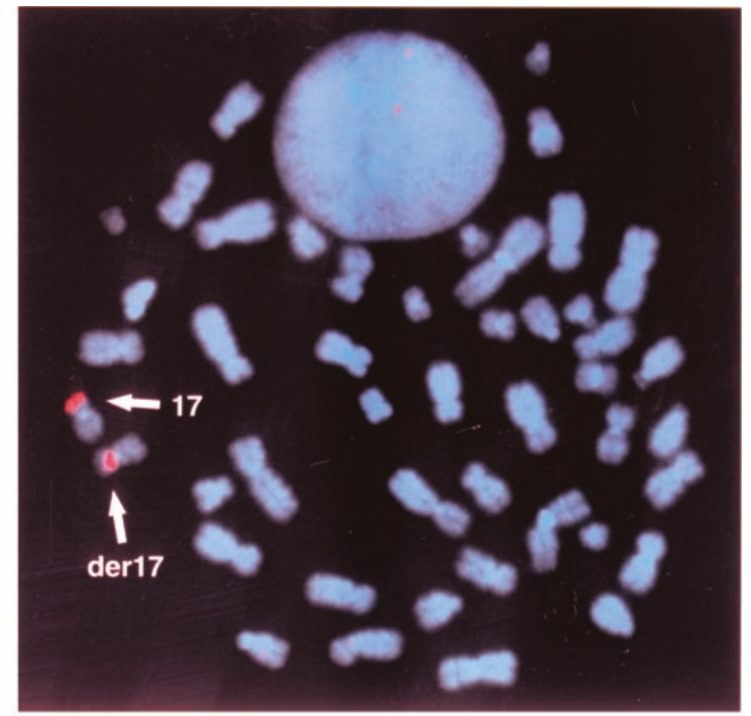

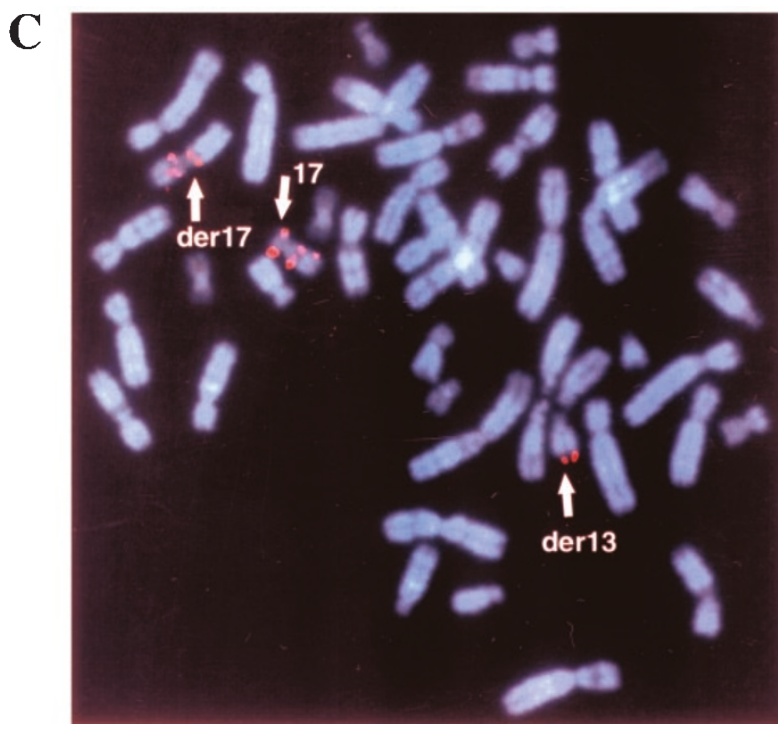

Figure 2 Fluorescent in situ hybridisation of the BAC clones (red signals) and to metaphase chromosomes from the patients. (A) Hybridisation of the BAC clone RP11-81A22 to chromosomes from the patient with $t(17 ; 19)$. The clone is detected on the native chromosome 17 and chromosome 19 derivative (arrows). (B) Hybridisation of the BAC clone RP11-305G1 to chromosomes from the patient with $\mathrm{t}(17 ; 19)$. The clone is detected on the native chromosome 17 and chromosome 17 derivative (arrows). (C) Hybridisation of the BAC clone RP11-4618 to chromosomes from the patient with $t(13 ; 17)$. The clone is detected on native chromosome 17 as well as the chromosome 13 and 17 derivatives (arrows). Additional red signals on the native 17 and der17 correspond to homologous sequences present on the chromosome 17.

$300 \mathrm{~kb}$ according to GenBank sequence data (Figure 1). The telomeric $17 \mathrm{p}$ breakpoint is located close to the $5^{\prime}$ end of CHRNE gene between the CHRNE and GP1BA genes whereas the centromeric $17 p$ breakpoint maps to a $25-30 \mathrm{~kb}$ region within the USP6 gene. The breakpoints are located approximately $2 \mathrm{Mb}$ centromeric to the LIS1 gene associated with the Miller-Dieker syndrome.

\section{Expression studies}

The region, which spans the chromosome 17 breakpoints in both patients, contains 14 known genes (Figure1). We hypothesise that the similar phenotype in both patients is related to the same gene(s) in the region. Expression analysis of all known genes located between the $17 \mathrm{p}$ breakpoints (Table 3) was performed using lymphoblastoid RNA derived from the two patients and six controls. After Northern slot 

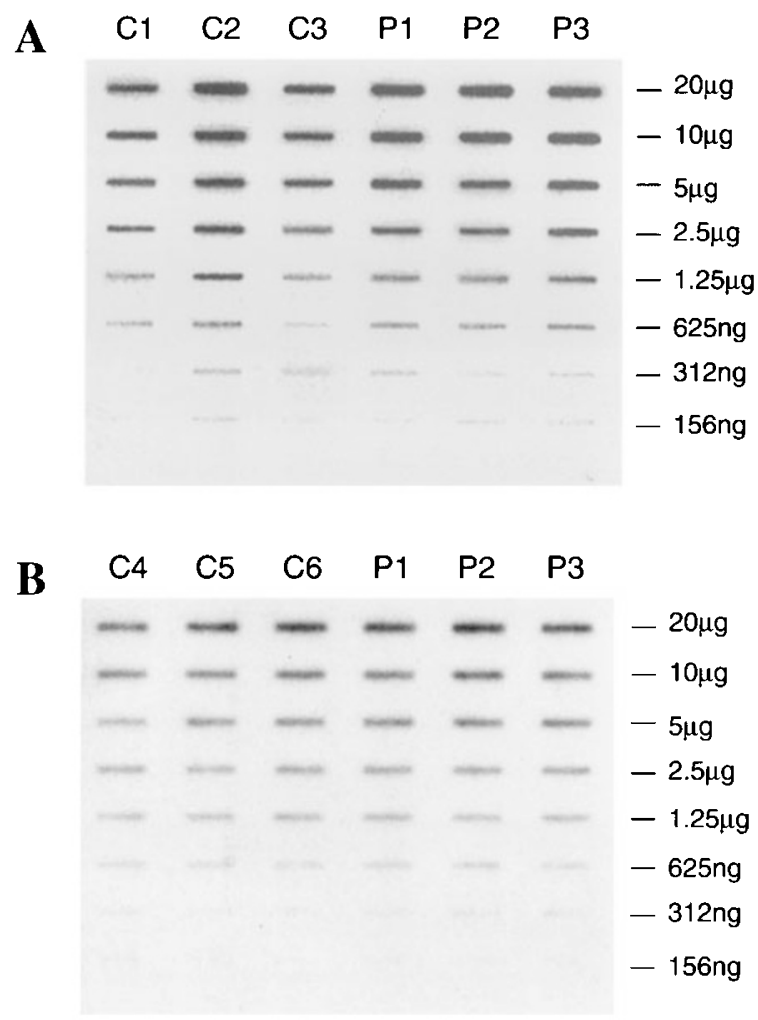

Figure 3 Northern slot hybridisation of the PFN1 oligonucleotide probe (Table 2) to lymphoblastoid RNA from the patients $(P)$ and normal controls (C). (A) Analysis of three independent cell lines from the patient with $t(17 ; 19)$ and three control individuals $($ C $1-C 3)$. (B) Analysis of three independent cell lines from the patient with $t(13 ; 17)$ and three control individuals (C4-C6). The amount of RNA applied per slot is indicated. Similar patterns from Northern slot analysis of RNA from the patients was found for the other genes located between the two chromosomal breakpoints.

hybridisations with oligonucleotide probes derived from mRNA sequences (Table 2), the level of expression was compared between the different cell lines. Total RNA was analysed from three independent cell lines from each patient, and from six control individuals. Expression levels of the CHRNE, DKFZP566H073, LOC90048, PFN1, SPAG7, KIAA0909, ZNF232 and KIF1C genes were found to be similar in the cell lines containing the translocations when compared to cell lines with the normal karyotype (Figure 3). No expression of the MINK1, MINK2, GP1BA, SLC25A11, ENO3, FLJ10060 and USP6 genes was detected in RNA from any of the cell lines.

\section{Discussion}

We present here the clinical, cytogenetic and molecular findings in two non-related patients with Asperger syndrome and balanced translocations involving chromosome 17. We found no indications of complex rearrangements or deletions associated with the two translocations.

An intensive search for genes behind autism has revealed a number of susceptibility loci. However, the results from several genomic screens are inconsistent. ${ }^{2,3}$ Autism is part of a wider spectrum of neuropsychiatric disorders with a considerable phenotypic variation (autism spectrum disorders) ${ }^{1}$ and the clinical diagnosis may be difficult. Differences in allele frequencies between various human populations as well as different definitions for the various autism spectrum disorders may be additional factors that influence the results. Autism is also a common associated problem of disorders including behaviour abnormalities such as Tourette syndrome, ADHD and obsessive-compulsive disorder. Therefore, it is possible that the phenotypic variation within autism and autism spectrum disorders reflects a difference in genetic factors, which stand behind these abnormalities.

In this report, we have analysed two patients diagnosed with Asperger syndrome without major associated symptoms. The patients presented here share two important features. Firstly, both patients have been diagnosed with Asperger syndrome by the same psychiatrists. Secondly, both patients have de novo chromosomal abnormalities, which involve a relatively small region on chromosome 17. These data suggest that the Asperger syndrome phenotype in both patients may be related to gene(s) or regulatory sequences located in the region. The fact that the mother and a half-sister of one of the patients have a history of behavioural abnormalities, which are not associated with $17 \mathrm{p}$ rearrangements, contradicts to this assumption. However, phenotypic differences between these individuals and complex inheritance of such traits raise the possibility that Asperger syndrome in the patient described here is caused by the $t(13 ; 17)$.

Fourteen genes have been mapped to the region between the two 17p breakpoints, and each gene is a potential candidate. In the present study, we investigated the mRNA expression from these candidate genes in cell lines with the translocations and in cell lines with a normal karyotype. Samples of a nervous tissue were impossible to obtain from the patients, and we restricted our analysis to EBV-transformed B-cells. We found no differences in mRNA expression of the genes CHRNE, DKFZP566H073, LOC90048, PFN1, SPAG7, KIAA0909, ZNF232 and KIF1C between cell lines carrying the translocations and normal cells. Expression of the MINK, GP1BA, SLC25A11, ENO3, FLJ10060 and USP6 genes was not detected in any cell line under the conditions used. Further analysis of expression levels in different cell types will be needed for the identification of candidate genes involved in the Asperger syndrome phenotype. The MINK1 and MINK2 genes are known to be involved in mouse brain development, and participate in signal-transduction cascades in nervous system, ${ }^{25}$ which makes them candidates for further expression analysis. 
In summary, we have identified a new susceptibility region for Asperger syndrome on 17p13 based on the molecular characterisation of two chromosome breakpoints. Further studies of the expression and function of genes located in the region may reveal candidate genes or regulatory sequences involved in the disease.

\section{Acknowledgements}

We thank Dr Nils-Erik Heldin and Dr Taras Stasyk for advice and technical assistance. This work was supported by grants from the Swedish Medical Research Council, Childrens Cancer Foundation of Sweden, the Swedish Cancer Society, the Söderström-Königska Foundation and the Swedish Medical Society, The Sävstaholm Society, Torsten and Ragnar Söderbergs Fund, The Lundbeck Foundation, the Borgström Foundation, and The Wilhelm and Martina Lundbergs Foundation.

\section{References}

1 Gillberg C, Billstedt E: Autism and Asperger syndrome coexistence with other clinical disorders. Acta Psychiatr Scand 2000; 102: $321-330$

2 Lamb JA, Moore J, Bailey A, Monaco AP: Austism: recent molecular genetic advances. Hum Mol Genet 2000; 9: 861-868.

3 Folstein SE, Rosen-Sheidley B: Genetics of autism: complex aetiology for a heterogeneous disorder. Nat Rev Genet 2001; 2: 943-955.

4 International Molecular Genetic Study of Autism Consortium: A full genome screen for autism with evidence for linkage to a region on chromosome 7q. Hum Mol Genet 1998; 7: 571-578.

5 Collaborative Linkage Study of Autism: An autosomal genomic screen for autism. Am J Med Genet 1999; 88: 609-615.

6 Philippe A, Martinez M, Guilloud-Bataille M et al: Genome-wide scan for autism susceptibility genes. Paris Autism Research International Sibpair Study. Hum Mol Genet 1999; 8: 805-812.

7 Risch N, Spiker D, Lotspeich L et al: A genomic screen of autism: evidence for a multilocus etiology. Am J Med Genet 1999; 65: 493 507.

8 Liu J, Nyholt DR, Magnussen P et al: A genomewide screen for autism susceptibility loci. Am J Hum Genet 2001; 69: 327-340.

9 Buxbaum JD, Silverman JM, Smith CJ et al: Evidence for a susceptibility gene for autism on chromosome 2 and for genetic heterogeneity. Am J Hum Genet 2001; 68: 1514-1520.

10 International Molecular Genetic Study of Autism Consortium: A genomewide screen for autism: strong evidence for linkage to chromosomes 2q, 7q, and 16p. Am J Hum Genet 2001; 69: 570581.

11 Alarcon M, Cantor RM, Liu J, Gilliam TC, Geschwind DH, Autism Genetic Research Exchange Consortium: Evidence for a language quantitative trait locus on chromosome $7 \mathrm{q}$ in multiplex autism families. Am J Hum Genet 2002; 70: 60-71.

12 Vincent JB, Herbrick JA, Gurling HMD, Bolton PF, Roberts W, Scherer SW: Identification of a novel gene on chromosome $7 \mathrm{q} 31$ that is interrupted by a translocation breakpoint in an autistic individual. Am J Hum Genet 2000; 67: 510-514.

13 Tentler D, Brandberg G, Betancur C et al: A balanced reciprocal translocation $\mathrm{t}(5 ; 7)(\mathrm{q} 14 ; \mathrm{q} 32)$ associated with autistic disorder: Molecular analysis of the chromosome 7 breakpoint. Am J Med Genet (Neuropsychiatr Genet) 2001; 105: 729-736.

14 Maestrini E, Lai C, Marlow A et al: Serotonin transporter (5-HTT) and $\gamma$-aminobutyric acid receptor subunit $\beta 3$ (GABRB3) gene polymorphisms are not associated with autism in the IMGSA families. Am J Med Genet (Neuropsychiatr Genet) 1999; 88: 492 496.
15 Salmon B, Hallmayer J, Rogers T et al: Absence of linkage disequilibrium to chromosome 15q11-q13 markers in 139 multiplex families with autism. Am J Med Genet (Neuropsychiatr Genet) 1999; 88: 551-556.

16 Gillberg C: Clinical and neurological aspects of Asperger syndrome in six family studies; in Frith U (ed): Austism and Asperger syndrome. Cambridge University Press: 1991; pp 122-146.

17 Gillberg C, Gillberg C, Rastam M, Wentz E: The Asperger Syndrome (and high-functioning autism) Diagnostic Interview (ASDI): a preliminary study of a new structured clinical interview. Autism 2001; 5: 57-66.

18 Lord C, Rutter M, Le Couteur A: Autism Diagnostic Interviewrevised: a revised version of a diagnostic interview for caregivers of individuals with possible pervasive developmental disorders. J Autism Dev Disord 1994; 24: 659-685.

19 Anneren G, Dahl N, Uddenfeldt U, Janols LO: Asperger syndrome in a boy with a balanced de novo translocation: $t(17 ; 19)$ (p13.3;p11). Am J Med Genet 1995; 56: 330-331.

20 Lichter P, Cremer T, Borden J, Manuelidis L, Ward DC: Delineation of individual human chromosomes in metaphase and interphase cells by in situ suppression hybridization using recombinant DNA libraries. Hum Genet 1988; 80: 224-234.

21 Pinkel D, Straume T, Gray JW: Cytogenetic analysis using quantitative, high-sensitivity, fluorescence in situ hybridization. Proc Natl Acad Sci USA 1986; 83: 2934-2938.

22 Albertsen $\mathrm{H}$, Thliveris A, Riley JH, Munroe DJ, Watkins P, Basson CT: Isolating total DNA from YAC-bearing yeast by spheroplast method; in Dracopoli NC, Haines JL, Korf BR, et al (eds): Current Protocols in Human Genetics. Wiley and Sons Inc., New York: 1998; pp 5,9,27-28.

23 Sambrook J, Fritsch EF, Maniatis T: Molecular cloning: a laboratory manual. 2nd edn. Cold Spring Harbor: Cold Spring Harbor Laboratory Press, 1989.

24 Barbu V, Dautry F: Northern blot normalization with 28 S oligonucleotide probe. Nucleic Acids Res 1989; 17: 7115.

25 Dan I, Watanabe NM, Kobayashi T et al: Molecular cloning of MINK, a novel member of mammalian GCK family kinases, which is up-regulated during postnatal mouse cerebral development. FEBS Lett 2000; 469: 19-23.

26 Beeson D, Brydson M, Betty $\mathrm{M}$ et al: Primary structure of the human muscle acetylcholine receptor. cDNA cloning of the gamma and epsilon subunits. Eur J Biochem 1993; 215: 229-238.

27 Lopez JA, Chung DW, Fujikawa K, Hagen FS, Papayannopoulou T, Roth GJ: Cloning of the alpha chain of human platelet glycoprotein Ib: a transmembrane protein with homology to leucine-rich alpha 2-glycoprotein. Proc Natl Acad Sci USA 1987; 84: 56155619.

28 Piccininni S, Iacobazzi V, Lauria G, Rocchi M, Palmieri F: Assignment of the oxoglutarate carrier gene (SLC20A4) to human chromosome 17p13.3. Cytogenet Cell Genet 1998; 83: 256-257.

29 Witke W, Sutherland JD, Sharpe A, Arai M, Kwiatkowski DJ: Profilin I is essential for cell survival and cell division in early mouse development. Proc Natl Acad Sci USA 2001; 98: 3832 - 3836.

30 Peshavaria M, Day IN: Molecular structure of the human musclespecific enolase gene (ENO3). Biochem J 1991; 275: 427-433.

31 Zhang QH, Ye M, Wu XY et al: Cloning functional analysis of cDNAs with open reading frames for 300 previously undefined genes expressed in CD34+ hematopoietic stem/progenitor cells. Genome Res 2000; 10: 1546-1560.

32 Dorner C, Ciossek T, Muller S, Moller PH, Ullrich A, Lammers R: Characterization of KIF1C, a new kinesin-like protein involved in vesicle transport from the Golgi apparatus to the endoplasmic reticulum. J Biol Chem 1998; 273: 20267-20275.

33 Mavrogiannis LA, Argyrokastritis A, Tzitzikas N et al: ZNF232: structure and expression analysis of a novel human $\mathrm{C}(2) \mathrm{H}(2)$ zinc finger gene, member of the SCAN/LeR domain subfamily. Biochim Biophys Acta 2001; 1518: 300-305.

34 Nakamura T, Hillova J, Mariage-Samson R et al: A novel transcriptional unit of the tre oncogene widely expressed in human cancer cells. Oncogene 1992; 7: 733-741. 